\title{
STUDIES ON VELOCITY FIELDS AROUND THE CAVITATION VORTICES GENERATED BY THE MODEL OF A ROTATING BLADE
}

\author{
Witold Suchecki \\ Warsaw University of Technology, The Faculty of Civil Engineering, Mechanics and Petrochemistry, \\ Institute of Mechanical Engineering, Department of Process Equipment, Poland
}

\begin{abstract}
The elimination of hazards caused by cavitation phenomena is an important issue to be considered in the design of process equipment including flow machinery. These hazards are: cavitation erosion, efficiency decrease as well as vibration and noise. One of the most intensive and dangerous forms of cavitation is vortex cavitation that accompanies the operation of hydraulic machines in which components comprised of rotating blades are applied.

Velocity fields around cavitation vortices generated by the model of a propeller blade were experimentally studied in a cavitation tunnel. Flow images were recorded using a high-speed camera and processed using particle image velocimetry (PIV) complemented with computer-aided techniques that had been developed for the purpose of this research. These techniques included the removal of image distortions on the basis of a calibration mask, determination of instantaneous velocity distributions and removal of air-bubble traces from flow images.

Experimental studies result examples were presented in the form of velocity fields determined in the longitudinal plane as well as in three transverse planes remote from the blade. Instabilities of the cavitating vortex stream and of the local liquid-flow velocity in its surrounding were detected. The effect of the angle of attack of propeller blade on the instability of the vortex stream and the effect of the presence of the cavitating vortex kernel on the local velocities of the surrounding liquid, were determined.
\end{abstract}

Keywords: experimental techniques,PIV,cavitation, rotary hydraulic machinery

\section{INTRODUCTION}

Controlled cavitation phenomena can play an important role in the operating principle of certain process equipment units like cavitational reactors (Ladino et al., 2016). However, more often, to ensure correct operation of process equipment, it is necessary to prevent uncontrolled cavitation from occurring (Campos-Amezcua et al., 2015). The avoidance of cavitation is a part of CFD-based design of modern rotary hydraulic machines like pumps, turbines and ship propulsors; the aim is to eliminate cavitation-induced hazards taking into account cavitation erosion, efficiency decrease as well as vibration and noise. One of the most intensive and dangerous forms of cavitation is the vortex cavitation that accompanies the operation of hydraulic machines in which components comprised of rotating blades (hydrofoils) are applied (Szantyr et al., 2011). As a result of liquid flow relative to the hydrofoil, a pressure distribution is generated. If the liquid is kept under atmospheric pressure, then under pressure occurs at the upstream face of the hydrofoil simultaneously with over pressure at its downstream face. When the absolute pressure at the upstream face decreases to the critical level, surface cavitation is initiated and a laminar vapor bubble is created; further pressure reduction causes the bubble to grow. At higher flow velocities, separation of the boundary layer may occur leading to the creation of a pulsating cloud of vapor bubbles (cavitation cloud) in the hydrofoil wake.

Investigations of ship propeller models in hydrodynamic tunnels have indicated that cavitation clouds can be formed 
as helical and axial vortices trailing the propeller. An axial vortex in which cavitation occurs is called a cavitating vortex kernel. First attempts to describe liquid flow around a ship propeller were based on classical equations of hydromechanics (Cumings, 1973). The methods of discrete vortex elements, sources and sinks (Kerwin, 1973) were widely applied. Recently, experimental investigations and numerical simulation of flow-velocity fields around cavitation vortices generated by the model of a propeller blade were carried out by Szantyr et al. (2011).

The experimental method of Particle Image Velocimetry (PIV) enables determination of the velocity vectors on the basis of measurement of displacement of particles between two correlated, consecutively recorded pictures created by laser light (Sanchez-Forero et al., 2015). In the research presented here, the pictures were recorded in time intervals of $250 \mu$ s by a high-speed camera. In order to provide sufficient number of micro-particles in the flow, necessary for effective PIV measurements, the water in the tunnel was seeded with silver metallic paint. The deflection of the light beam when crossing the window-water boundary was taken into account. The results of PIV measurements were stored in computer files and then filtered and re-calculated using specialized custom software (Suchecki, 2014).

In the present paper, the methodology of experimental research is presented along with examples of flow velocity fields with comments. Methods of flow images distortions removal using a calibration mask and to remove air-bubble traces from flow images are briefly described.

\section{EXPERIMENTAL UNIT}

The research was conducted in the cavitation tunnel of the Department of Rotating Machines and Mechanics of Liquids of Gdansk University of Technology.

\section{EXPERIMENTAL FACILITY}

The experimental facility used is shown in Fig. 1.

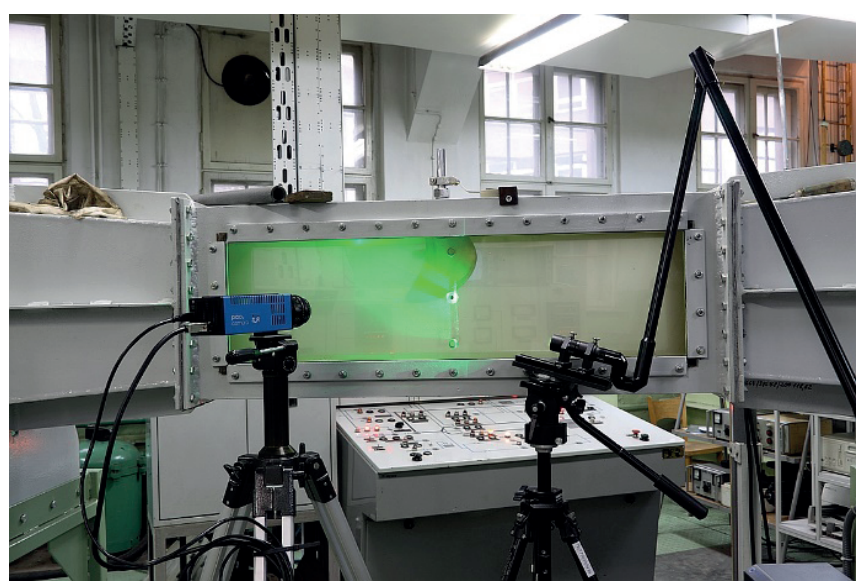

Fig. 1. Cavitation tunnel during PIV measurements
The cavitation tunnel has a rectangular measuring section with dimensions of $3.0 \times 0.35 \times 0.45 \mathrm{~m}$. The maximum flow velocity in the tunnel is $6 \mathrm{~m} / \mathrm{s}$.

The hydrofoil model used in the experiments was specially designed on the basis of the typical contemporary marine propeller blade geometry, which was deployed onto a plane surface. In order to ensure that cavitating tip vortex location was approximately in the center line of the measuring section, the hydrofoil span was selected equal to $225 \mathrm{~mm}$ (Fig. 3). The hydrofoil was manufactured out of bronze and mounted vertically in the tunnel by means of a mechanism that enables accurate control of the angle of attack.

PIV measurements were conducted for a number of different conditions resulting from combinations of the values of the angle of attack and flow velocity. These conditions are listed in Tab. 1, together with the locations of three measurement planes. In order to visualize the formation of the cavitating tip vortex, the planes were positioned perpendicular to the tunnel axis and located 50, 200 and $300 \mathrm{~mm}$ behind the tip of the hydrofoil. The combination of all parameter values listed in Tab. 1 produced 27 measurements of the flow-velocity distribution.

During the experiments the static pressure in the tunnel was kept constant at $15 \mathrm{kPa}$. The cavitation index is defined according to the (1):

$$
\sigma=\frac{\mathrm{p}-\mathrm{p}_{\mathrm{kr}}}{0.5\left(\rho \mathrm{V}^{2}\right)}
$$

where:

$\mathrm{p}$ - static pressure in the tunnel,

$\mathrm{p}_{\mathrm{kr}}$ - critical vapor pressure,

$\rho$ - liquid density,

$\mathrm{V}$ - average flow velocity.

Tab. 1. Conditions fir PIV measurements

\begin{tabular}{|c|c|c|c|}
\hline $\begin{array}{c}\text { Distance } \\
\text { behind the } \\
\text { hydrofoil } \\
\text { tip } \\
{[\mathrm{mm}]}\end{array}$ & $\begin{array}{c}\text { Average flow } \\
\text { velocities }\end{array}$ & $\begin{array}{c}\text { Angles } \\
\text { of attack } \\
{[\mathrm{m} / \mathrm{s}]}\end{array}$ & Cavitation indices \\
\hline 50 & $4.32,5.09,5.87$ & $4,8,12$ & $1.393,1.003,0.755$ \\
\hline 200 & $4.32,5.09,5.87$ & $4,8,12$ & $1.393,1.003,0.755$ \\
\hline 300 & $4.32,5.09,5.87$ & $4,8,12$ & $1.393,1.003,0.755$ \\
\hline
\end{tabular}

\section{PIV METHOD}

The measurement system schematic shown in Fig. 2 consists of the laser dual-Nd:YAG, New Wave 120XT-15Hz and high-speed pco.1200hs camera.

The distances of camera $\mathrm{K}$ from the measuring section were kept constant at $b=570 \mathrm{~mm}$ and $\mathrm{c}=668 \mathrm{~mm}$. The distance of the laser $\mathrm{L}$ from the measuring section was constant and equal to $\mathrm{a}=44 \mathrm{~mm}$. The distances between the measuring plane and hydrofoil tip were varied at: $d=50$, 200 and $300 \mathrm{~mm}$. The system was arranged in such a way that 
the angle between the laser light plane and camera axis was approximately $45^{\circ}$ in all measurements.

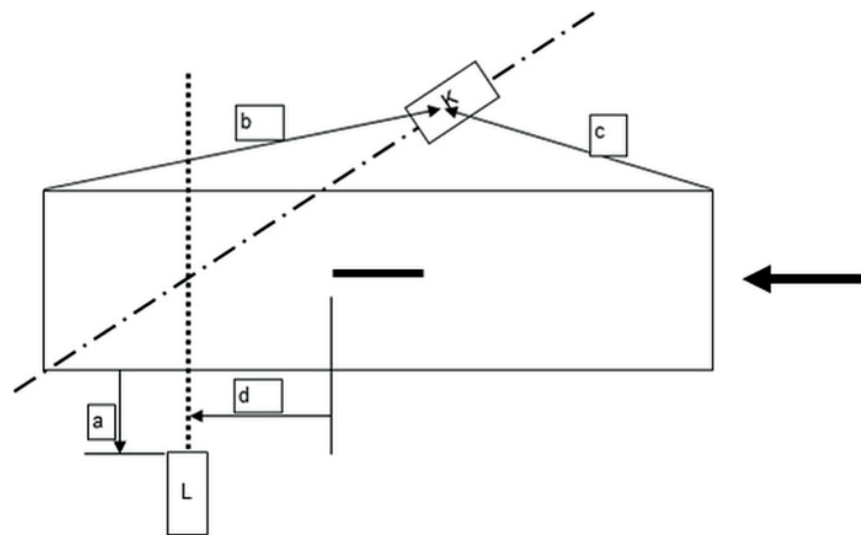

Fig. 2. Scheme of the measuring system

Fig. 3 shows the laser light in the measuring plane $50 \mathrm{~mm}$ behind the hydrofoil tip during PIV measurements. Apart from PIV measurements, photographs of the cavitating tip vortex were recorded. A complete description of the measurements may be found in Suchecki and Alabrudzinski (2011).

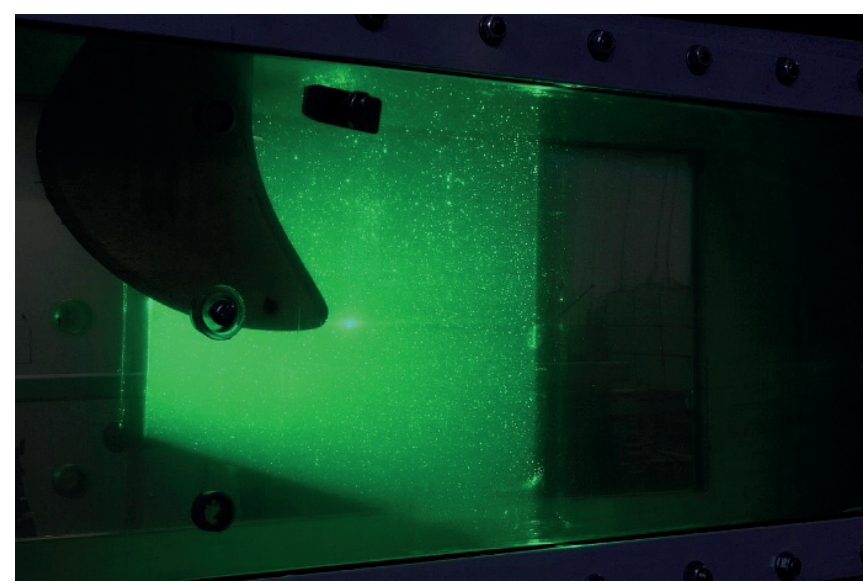

Fig. 3. PIV measurement plane behind the tip of the hydrofoil

\section{REMOVAL OF IMAGE DISTORTIONS}

Owing to light refraction in the channel wall and flowing liquid, the recorded flow images were optically distorted. In order to exactly determine the angle between the laser light plane and camera axis, the values of refractive indices of the channel wall and liquid should be accounted for. However, instead of measuring the refractive indices, so-called calibration masks were used (Fig. 4). After completing the flow experiments, an orthogonal calibration grid of known dimensions was placed parallel to the light plane and its image was recorded thus making it possible to calculate correction coefficients needed for geometrical transformation of the recorded flow images. After carrying out the transformation, the diagrams of calculated flow-velocity fields could be determined in their true positions on the measurement plane.

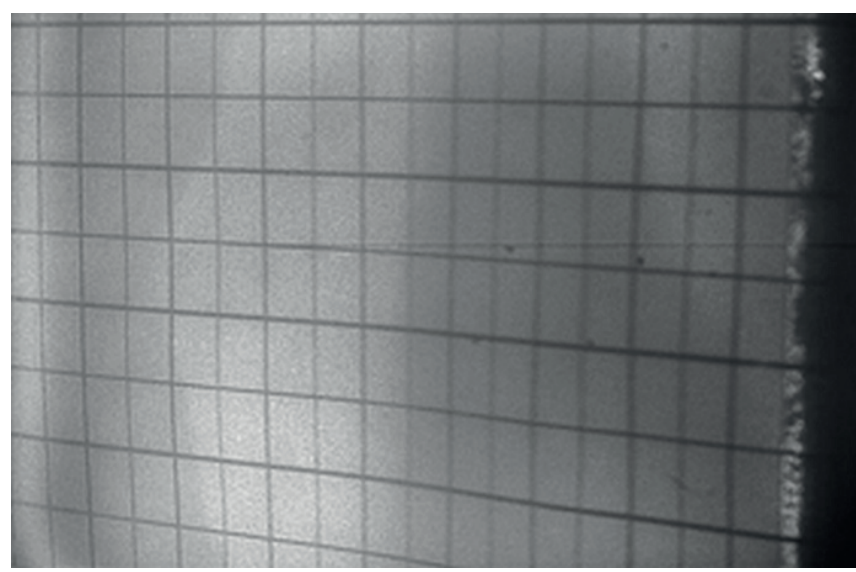

Fig. 4. View of calibration mask

Another distortion of flow images resulted from the positioning of camera axis at an angle different from 90 degrees relative to the light plane denoted $\mathrm{P}$ in Fig. 5. In consequence, instead of determining flow-velocity vectors in the light plane, projections of these vectors on plane $\mathrm{P}^{\prime}$ perpendicular to the camera axis were determined.

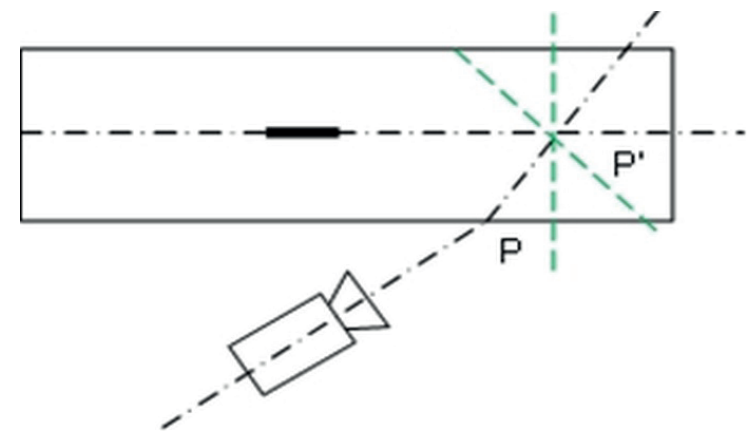

Fig. 5. Positions of the measurement (laser-light) plane $P$ and plane $P$ perpendicular to the camera axis

In the calculated flow-velocity fields, the origin of the coordinate system is placed close to the position of the cavitating vortex kernel so as to enable visualization of flow-velocity distribution around the kernel. The diagrams of flow-velocity fields so determined are presented in Section 3.

\section{REMOVAL OF AIR-BUBBLE TRACES FROM FLOW IMAGES}

As the liquid flows through the cavitation tunnel, gas bubbles may occur potentially disturbing PIV-based determination of flow-velocity distribution. In order to prevent the disturbances from affecting the quality of PIV results, the recorded flow images were processed by local binarization, that is, each image was divided into sections of predefined size and binarization with predefined threshold was sequentially applied to the image sections. After that, PIV calculations were carried out using the binarized image. An example of flow image with visible gas-bubble traces together with the image version obtained by local binarization is shown in Fig. 6. 

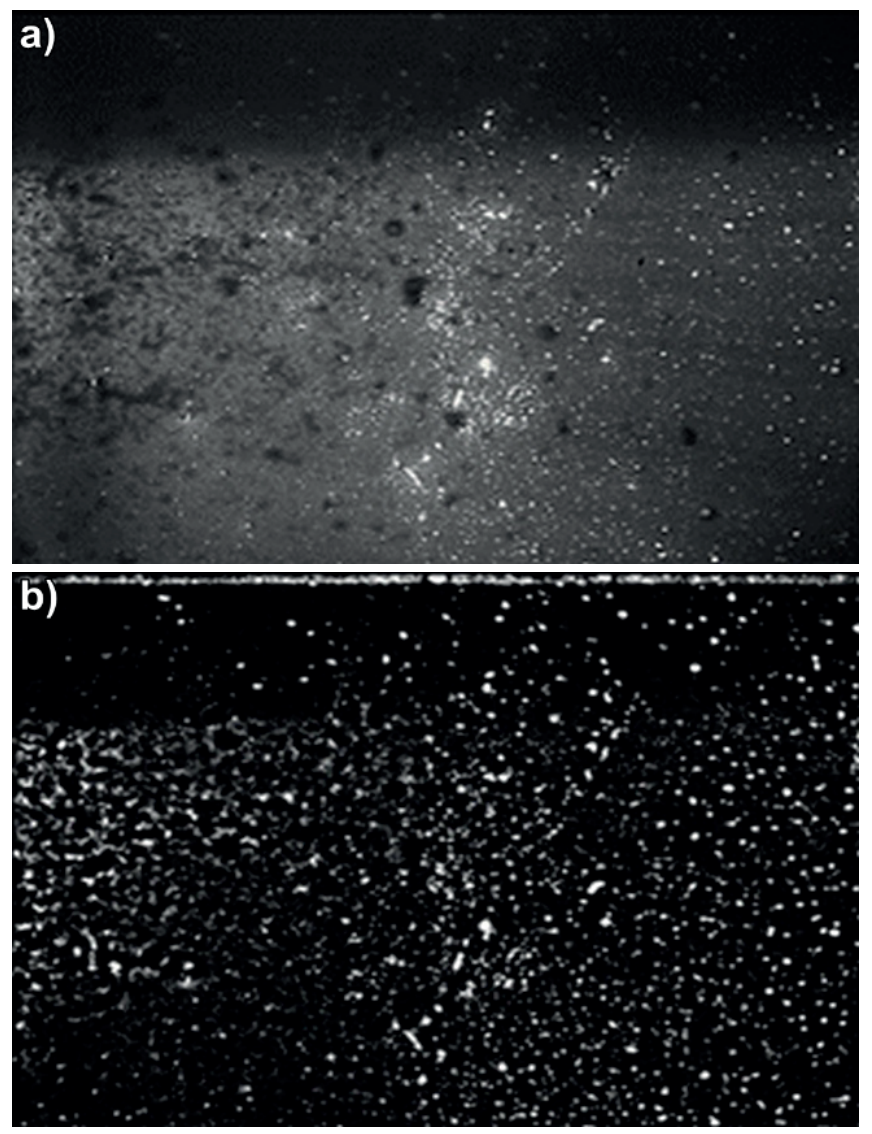

Fig. 6. Flow image recorded in $200 \mathrm{~mm}$ cross-section at average flow velocity of $5.87 \mathrm{~m} / \mathrm{s}$ and angle of attack $12^{\circ}(a)$ and corresponding image after local binarization (b)

\section{RESULTS AND DISCUSSION}

Examples of flow velocity fields are presented using flow velocity maps determined in transverse planes at 50,200 and $300 \mathrm{~mm}$ distance from the hydrofoil, at two values of the angle of attack: 4 and 12. The average flow velocity was $5.87 \mathrm{~m} / \mathrm{s}$. The distribution of flow velocity vectors was determined using the least-squares approach.

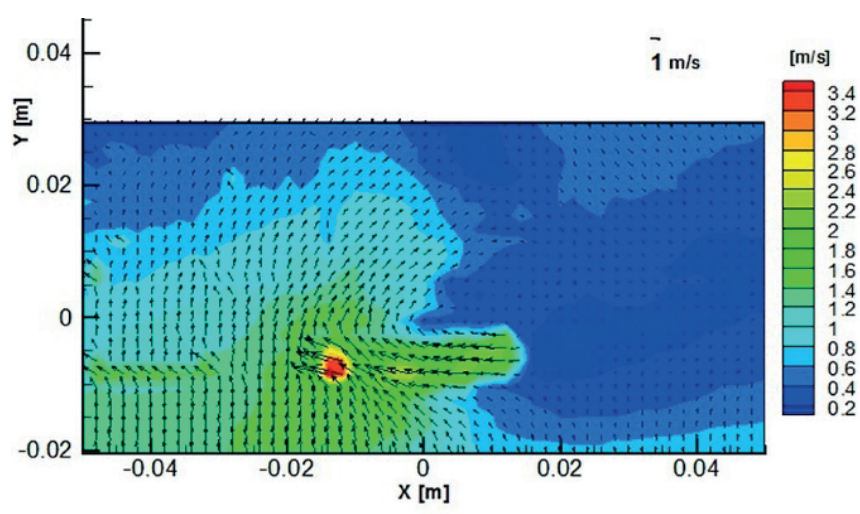

Fig. 7. Measured velocity field in plane at the distance $50 \mathrm{~mm}$, angle of attack 4 degrees

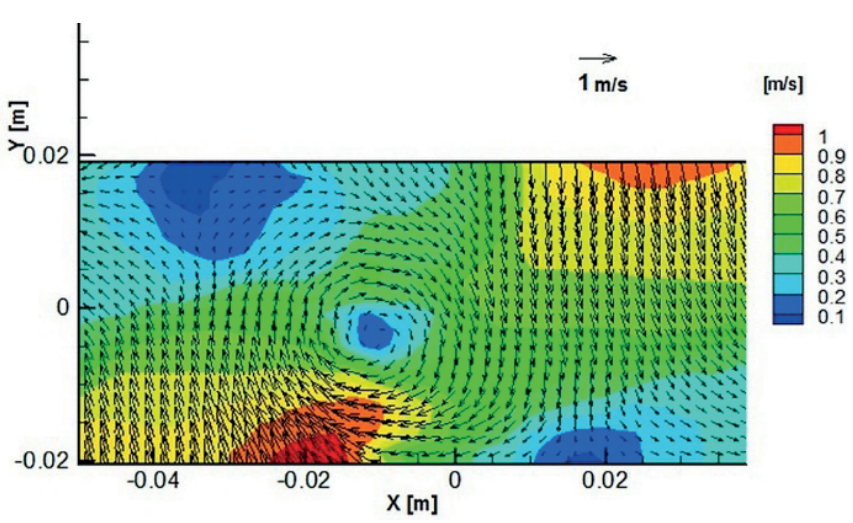

Fig. 8. Measured velocity field in plane at the distance $200 \mathrm{~mm}$, angle of attack 4 degrees

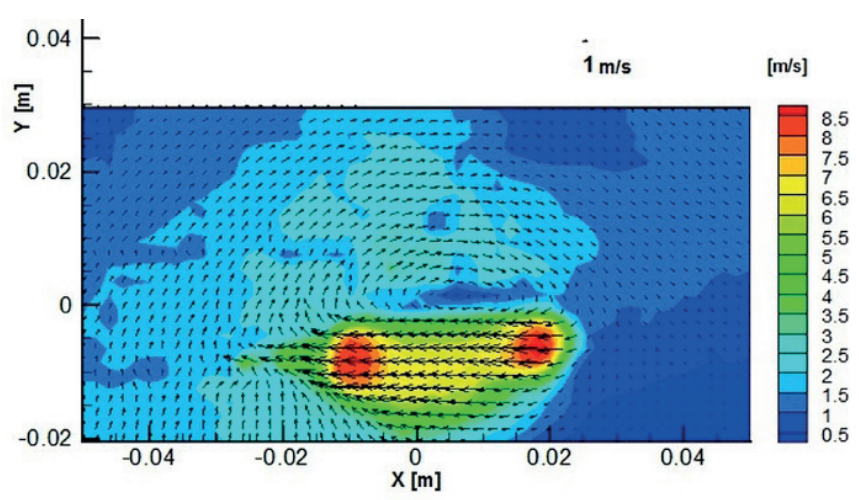

Fig. 9. Measured velocity field in plane at the distance $50 \mathrm{~mm}$, angle of attack 12 degrees

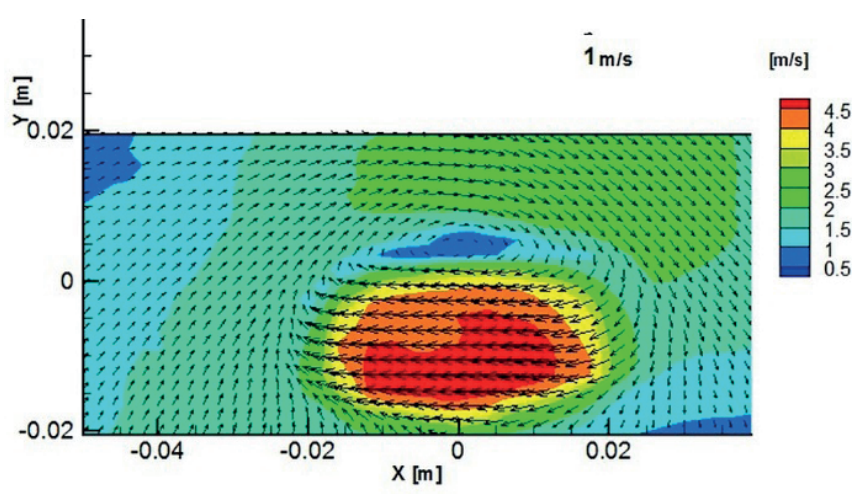

Fig. 10. Measured velocity field in plane at the distance $300 \mathrm{~mm}$, angle of attack 12 degrees

Compared to the results of early research (Noordzij, 1976) and its later extensions (Singhal et al., 2002) including the most recent work (Ji et al., 2012), the present results considerably improve the understanding of cavitating flows around moving blades. At the angle of attack of 4 , the structure of the kernel of cavitating vortex is clearly visible (Fig. 7 and 8). As the angle changes to 12 , two kernels appear at $50 \mathrm{~mm}$ distance from the hydrofoil (Fig. 9) and another blurry kernel is visible at $300 \mathrm{~mm}$ distance (Fig. 10). This may be due to the instability of the vortex stream and light scattering on the stream where gas-liquid mixture is present. 
Owing to space limitation, the results of experiments performed at other values of the average flow velocity are not shown here. It was found that increased angle of attack was the primary cause of flow instability whereas the influence of average flow velocity was less important. The instability of the vortex stream increased with distance from the hydrofoil. As the kernel of cavitating vortex was separated from the hydrofoil, the local flow velocities in the surrounding liquid close to the hydrofoil surface were significantly affected.

\section{CONCLUSIONS}

Apart from contributing to the knowledge of cavitating flows around rotating blades, the presented research results indicate that PIV measurements of the velocity field in the vicinity of the cavitating tip vortex constitute a difficult and challenging task. The reasons for that are following: unsteady oscillations of the cavitating vortex kernel,

- uncontrolled concentration of the cavitation nuclei (i.e. gas- and vapor-filled micro-bubbles) carried by the flowing water,

- partial shading of the measuring plane by the cavitating vortex kernel,

- difficulties in homogenous PIV seeding due to the large volume of fluid inside the cavitation tunnel and complex flow conditions near the cavitating tip vortex where centrifugal force is acting on the seed particles.

Providing that the model geometry is correctly matched with the geometry of the cavitation tunnel, most experimental difficulties can be overcome by properly selecting the light sources and their configuration, and also by optimizing the resolution of flow images and time-step of the image recording.

\section{BIBLIOGRAPHY}

1. Campos-Amezcua R., Bakir F., Campos-Amezcua A., Khelladi S., Palacios-Gallegos M., Rey R.: Numerical analysis of unsteady cavitating flow in an axial inducer, Applied Thermal Engineering, 75, 2015, pp. 1302-1310.

2. Cumings D.E.: Numerical prediction of propeller characteristics, J. Ship Res., 17(1), 1973, pp. 12-18.

3. Ji B., Luo X., Peng X., Wu Y., Xu H.: Numerical analysis of cavitation evolution and excited pressure fluctuation around a propeller in non-uniform wake, International Journal of Multiphase Flow, 43, 2012, pp. 13-21.

4. Kerwin J.: Computer techniques for propeller blade section design, Int. Shipbuilding Progress, 20(227), 1973, pp. 227-251.

5. Ladino J.A., Herrera J., Malagón D.H., Prisciandaro M.,, Piemonte V., Capocelli M.: Biodiesel production via hydrodynamic cavitation: numerical study of new geometrical arrangements, Chemical Engineering Transactions, 50, 2016, pp. 319-324.

6. Noordzij L.: Pressure field by a cavitating propeller, Int. Shipbuilding Progress, 23(260), 1976, pp. 93-105.

7. Sanchez-Forero D.I., Klock Da Costa K., Amaral R.L., Taranto O.P., Mori M.: Influence of liquid viscosity and solid load in a three-phase bubble column using stereoscopic particle image velocimetry (stereo-PIV), Chemical Engineering Transactions, 43, 2015, pp. 1579-1584.

8. Singhal A.K., Athavale M.M, Li H., Jiang Y.: Mathematical Basis and Validation of the Full Cavitation Model, Journal of Fluids Engineering, 124(3), 2002, pp. 617-624.

9. Suchecki W., Alabrudziński S.: Research Report - Task 1, Experimental Measurements of the Cavitating Vortex Kernel and Velocity in its Close Vicinity, Warsaw University of Technology, Poland (in Polish) 2011.

10. Suchecki W.: Research on liquid flow in industrial apparatuses by means of both visualization and numerical simulation methods, Warsaw University of Technology Publishing House, Warsaw, Poland (in Polish) 2014.

11. Szantyr J.A., Flaszyński P., Tesch K., Suchecki W., Alabrudziński S.: An Experimental and Numerical Study of Tip Vortex Cavitation, Polish Maritime Research, 4(71), 18, 2011, pp. 14-22.

\section{CONTACT WITH THE AUTHOR}

\author{
Witold Suchecki \\ e-mail: Witold.Suchecki@pw.edu.pl \\ Warsaw University of Technology \\ The Faculty of Civil Engineering \\ Mechanics and Petrochemistry \\ Institute of Mechanical Engineering \\ Department of Process Equipment \\ Jachowicza $2 / 4$ \\ 09-402 Płock \\ Poland
}

